\title{
Upright MRI after decompression of spinal stenosis and concurrent spondylolisthesis
}

\author{
Michael Kern, ${ }^{1}$ Matthias Setzer, MD, PhD, ${ }^{1}$ Lutz Weise, MD, PhD, ${ }^{1}$ Ali Mroe, MD, ${ }^{2}$ Holger Frey, MsE, ${ }^{2}$ \\ Katharina Frey, ${ }^{2}$ Volker Seifert, MD, PhD, ${ }^{1}$ and Stephan Duetzmann, MD, MSc ${ }^{1}$ \\ 1Department of Neurosurgery, University of Frankfurt; and ${ }^{2}$ Center for Upright MRI, Frankfurt, Germany
}

\begin{abstract}
OBJECTIVE The treatment of patients with spinal stenosis and concurrent degenerative spondylolisthesis is controversial. Two large randomized controlled clinical trials reported contradictory results. The authors hypothesized that a substantial number of patients will show evidence of micro-instability after a sole decompression procedure.

METHODS This study was a retrospective analysis of all cases of lumbar spinal stenosis treated at the Frankfurt University Clinic (Universitätsklinik Frankfurt) from 2010 through 2013. Patients who had associated spondylolisthesis underwent upright MRI studies in flexion and extension for identification of subtle signs of micro-instability. Clinical outcome was assessed by means of SF-36 bodily pain (BP) and physical functioning (PF) scales.
\end{abstract}

RESULTS A total of 21 patients were recruited to undergo upright MRI studies. The mean duration of follow-up was 65 months (SD 16 months). Of these 21 patients, 10 (47\%) showed signs of micro-instability as defined by movement of $>4$ $\mathrm{mm}$ on flexion/extension MRI. Comparison of mean SF-36 BP and PF scores in the group of patients who showed microinstability versus those who did not showed no statistically significant difference on either scale.

CONCLUSIONS There seems to be a substantial subset of patients who develop morphological micro-instability after sole decompression procedures but do not experience any clinically significant effect of the instability.

https://thejns.org/doi/abs/10.3171/2019.3.FOCUS18730

KEYWORDS upright MRI; spondylolisthesis; spinal canal stenosis

$\mathrm{T}$ HE treatment of spinal stenosis and degenerative spondylolisthesis is controversial. Two large randomized clinical trials reported contradictory results. ${ }^{10,11}$ Recent registry clinical outcome data could not prove superiority of upfront fusion. ${ }^{4}$ It is obvious that the complex spinal anatomy and clinical history of each patient mandates individual decision making. The fusion procedure can address not only the stenosis but also the sagittal balance, and improved balance can lead to better outcome. ${ }^{23}$ On the other hand the convergence of several demographic trends, including financial pressures and an aging population with increased comorbidities, have motivated surgeons to attempt to improve patient outcomes, decrease costs, and minimize surgical trauma ${ }^{2}$ by performing less invasive surgical techniques such as a minimally invasive sole decompression. ${ }^{1}$

None of the studies that were performed after the publication of the Swedish randomized trial ${ }^{10}$ could explain the good results of the decompression-only procedure compared to the fusion procedure, although superiority of the fusion procedure was found in previous studies by Herkowitz and Weinstein., ${ }^{9,13,22}$ The speculation that the Swedish patients were treated less aggressively with tension-band sparing techniques is false, since $80 \%$ were treated with a laminectomy.

At our institution we have generally treated patients with degenerative spondylolisthesis via a sole decompressive procedure because we did not feel that the benefit of the fusion procedure that was reported in the SPORTs trial $^{22}$ and the Herkowitz studies ${ }^{9,13}$ justified the additional operative morbidity. ${ }^{6}$

Nevertheless, it is possible that many patients could develop micro-instability ${ }^{7}$ and be on the way to clinically significant instability but not yet have obvious symptoms of instability. ${ }^{18,19}$ Previous analysis of radiographic data showed a slip progression rate in 5 years of only $8 \%$ in 


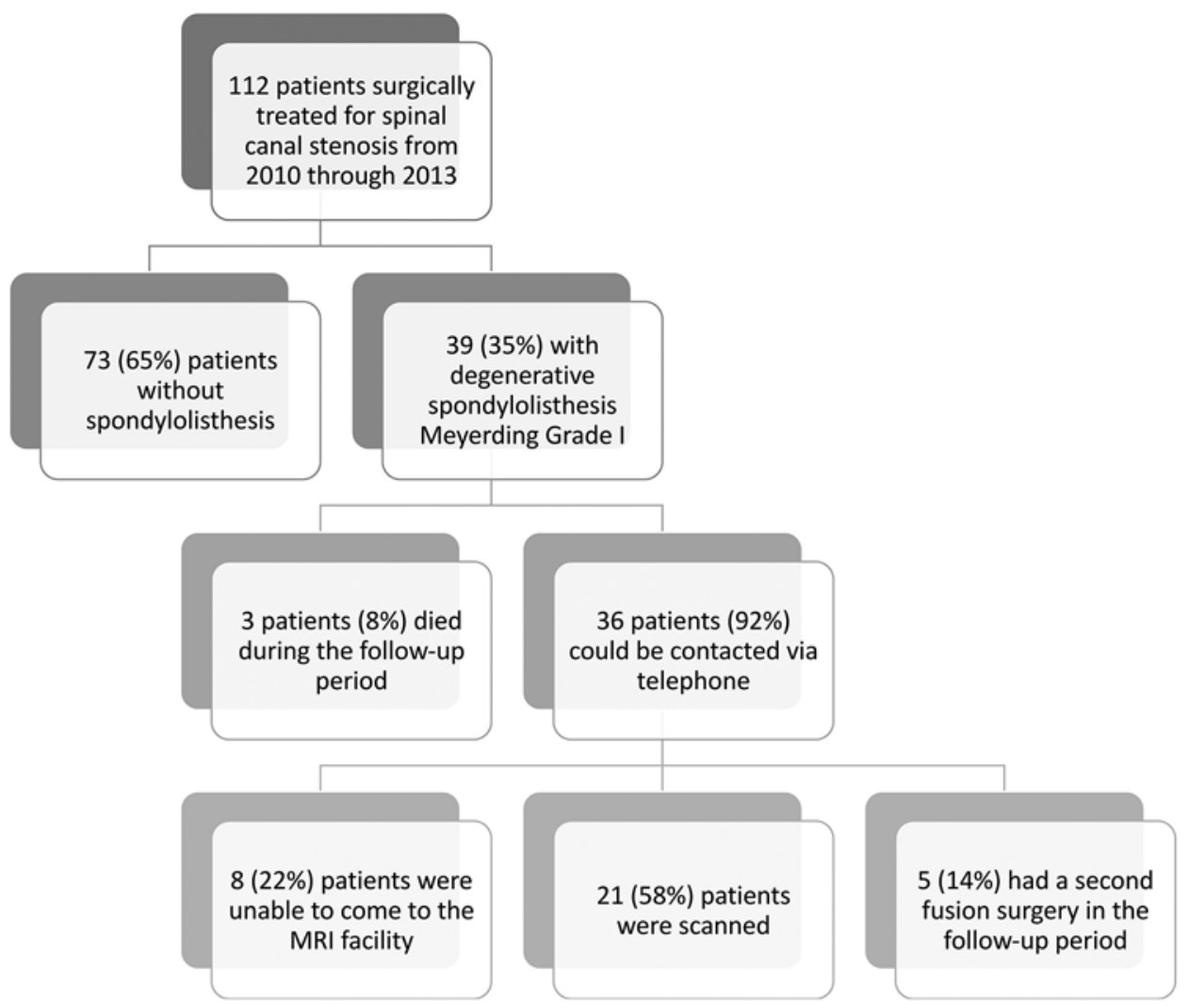

FIG. 1. Flowchart of our patient selection.

flexion/extension radiographs. ${ }^{5}$ We hypothesized that the actual rate was much higher and that radiographs represent a rather crude method to detect this. Thus we conducted a retrospective analysis of cases involving patients treated from 2010 through 2013 and conducted upright MRI studies in flexion and extension to identify subtle signs of instability and long-term changes. Patient also were clinically assessed at the time of the MRI via SF-36.

\section{Methods}

Institutional review board approval was obtained by the regional university board committee (Ethikkommission der Universitätsklinik Frankfurt).

\section{Patient Selection}

We conducted a retrospective analysis of cases of lumbar spinal stenosis treated at our institution from 2010 through 2013. All patients who underwent decompressive lumbar surgery without instrumentation in the form of a unilateral laminotomy and those with degenerative lumbar olisthesis of Meyerding grade I were included in our study. Patients who had an instrumentation procedure upfront were excluded.

Patients were contacted and asked if they were willing to have an upright MRI performed at our partner center for upright MRI studies.

Instability was defined as movement of the vertebral body of more than $2 \mathrm{~mm}$ in flexion and extension MRI as seen in the midline of the sagittal T2-weighted image. The index level and 2 levels above the index level were evaluated for movement.

Clinical follow-up was assessed at the time of the MRI. Clinical outcome was assessed via the SF-36 bodily pain (BP) and physical function (PF) scales since Pearson et al. reported using these measures to analyze the data of the SPORTS trial. ${ }^{22}$

\section{MRI Examination}

The examination was performed in a Fonar Upright MRI with the following patient positions and MRI sequences: sitting in neutral position-sagittal T2-weighted, axial T2-weighted, and coronal 3D-gradient echo; sitting in flexion position-sagittal T2-weighted, axial T2weighted; and standing in extension position-sagittal T2weighted, axial T2-weighted. Due to technical reasons the extension position was not assessed in the sitting position.

\section{Results}

Patient selection is depicted in Fig. 1. No patient received an upfront fusion procedure during the study period. A total of 39 patients were eligible for the study. Three patients died during the follow-up period (8\%). We were able to contact all 36 of the remaining patients. Two patients declined to respond. Five (14\%) had received a second fusion surgery. Eight patients $(22 \%)$ were not able to get to the MRI facility and were questioned via telephone.

We thus could recruit 21 patients to undergo upright MRI studies. Basic patient demographic data are shown 
TABLE 1. Summary of basic demographic and clinical variables for the 21 patients who underwent upright MRI

\begin{tabular}{lc}
\hline Mean age & \\
\hline Mean & 70.0 \\
\hline SD & 5.6 \\
\hline Male/female ratio & $1: 1.6$ \\
\hline Surgically treated level & $16(76 \%)$ \\
\hline L4-5 & $3(16 \%)$ \\
\hline L3-4 & $2(10 \%)$ \\
\hline L5-S1 & $21(100 \%)$ \\
\hline Open microscopic op via unilateral decompression
\end{tabular}

in Table 1. The mean duration of follow-up was 65 months (SD 16 months).

All 21 of these patients (100\%) described their clinical status as better than before the surgery.

Overall (including non-scanned patients), the mean SF36 BP score was 48 (SD 11) and the mean SF-36 PF Score was 50 (SD 8). The mean SF-36 BP and PF scores for the scanned patients were 48 (SD 10) and 49 (SD 7), respectively.

\section{Signs of Micro-Instability}

Of the 21 patients who underwent upright MRI exami- nations, 10 (47\%) showed signs of instability (Fig. 2). Eleven patients did not show slippage of the vertebral body at the treated level.

The mean follow-up for the group that showed microinstability was 64 months (SD 17 months) and that for those who did not show any instability was 66 months (SD 17 months).

In the patients who showed micro-instability, the mean SF-36 BP and PF scores were 46 (SD 9) and 49 (SD 8), respectively, while the corresponding scores for those who did not show any instability were 51 (SD 12) and 51 (SD 7). The difference was not statistically significant (BP: $p=$ 0.33; PF: $\mathrm{p}=0.44$; t-test).

None of the levels above the index surgery level showed any slippage in flexion and extension.

The overall mean disc height at the treated level (for all 21 scanned patients) was $8.2 \mathrm{~mm}$ (SD 1.8). The mean disc height was the same for the patients who showed microinstability and those who did not $(8.2 \mathrm{~mm})$, but the standard deviation differed $-2.6 \mathrm{~mm}$ in the group that showed micro-instability and $1.6 \mathrm{~mm}$ in the group that did not.

None of the imaging studies showed any adjacent-segment degeneration.

\section{Fused Cohort}

The 5 patients who underwent fusion were symptomatic with instability-related back-pain within a year after
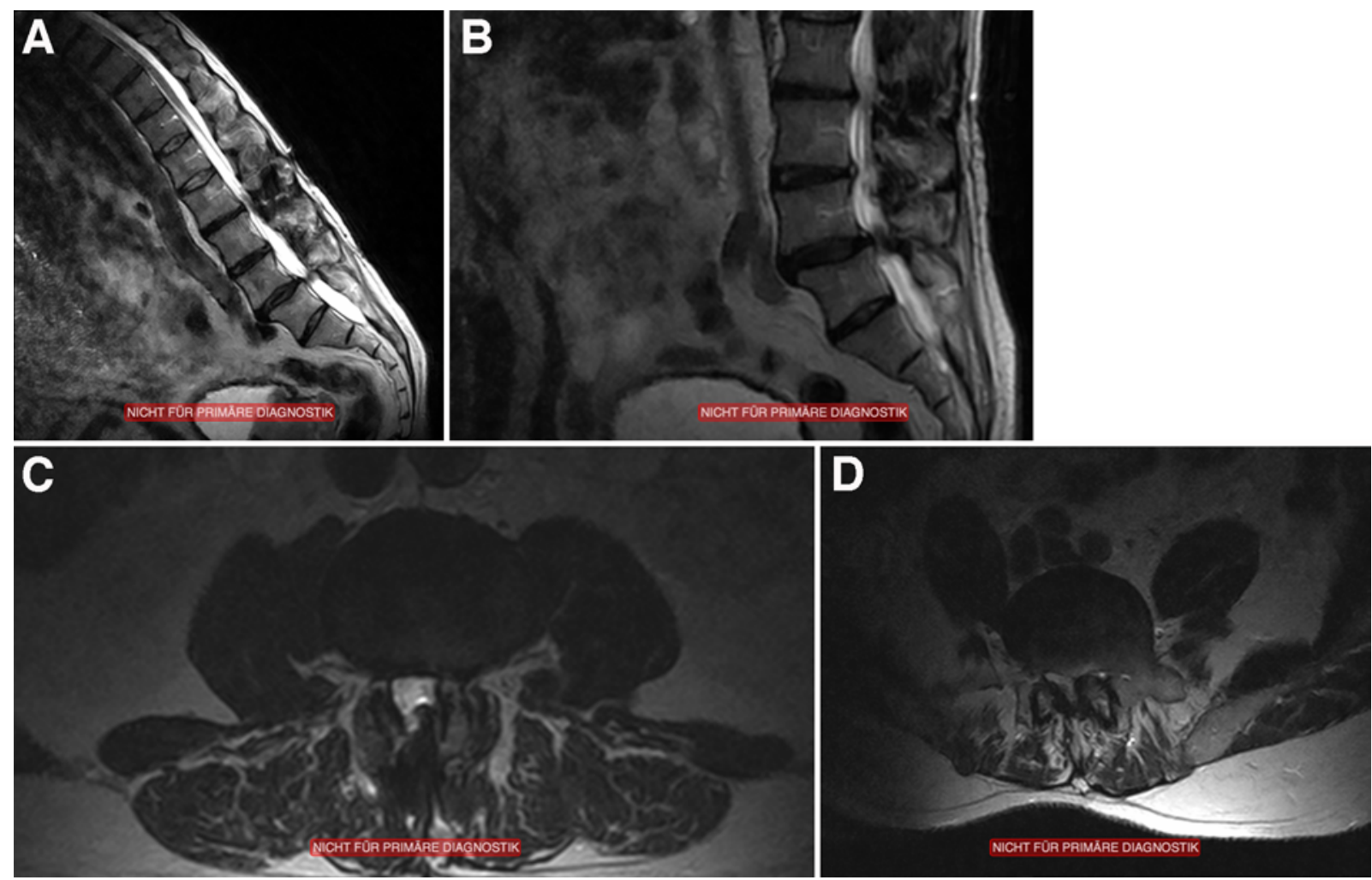

FIG. 2. MR images obtained in a single patient in different positions. This patient did not complain of new or recurrent symptoms. $A$ and B: Sagittal T2-weighted MR images obtained with the patient flexed forward (A) and in the standing extension position (B). A movement of $4 \mathrm{~mm}$ of $L 4$ can be seen. $C$ and D: Axial T2-weighted MR images of the level of the listhesis obtained with the patient flexed forward $(C)$ and in the standing extension position (D). The dysfunctional movement of the facet joint is evident in comparison of these 2 images. 
the index surgery. When we contacted them, the vertebrae were already fused and thus none of them were eligible for the upright imaging analysis. Nonetheless, we reviewed their preoperative images and included the findings in a separate analysis to see if we could find predictors of instability.

The mean preoperative disc height at the index level in these 5 patients was 8.1 (SD 1.8); comparison to the mean value for the 21 patients who did not undergo fusion procedures showed no statistically significant difference $(\mathrm{p}=0.38)$. The mean SF-36 BP score was 45 (SD 9) and the mean SF-36 PF score was 48 (SD 9); again, neither was significantly different from the corresponding values in the nonfused cohort.

\section{Discussion}

This is the first study to utilize upright MRI studies in flexion and extension in patients who had previously undergone decompressive surgery for degenerative olisthesis. Since the publication of the 2 landmark studies on degenerative spondylolisthesis, ${ }^{10,12}$ it is unclear why the Swedish study (Försth et al. ( $^{10}$ did not reveal the superiority of the fusion procedure, despite previous evidence, ${ }^{9,13}$ while recent evidence suggests at least equality as measured by various important outcome parameters such as Oswestry Disability Index scores and opioid dependence rates., ${ }^{4,26}$

Regional, cultural, and socioeconomic biases against fusion as well as differences in surgical technique and experience have been speculated as reasons for the equal performance of the fusion group in the Swedish study. ${ }^{28}$ Furthermore, the Swedish study included patients with stable as well as unstable vertebrae, with instability defined as slippage of more than $4 \mathrm{~mm}$ in flexion/extension radiographs, and did not differentiate between the 2 groups. ${ }^{10,27}$

Our overall mean SF-36 PF score of 48 is approximately equal to that of the fusion group of the SLIP trial (45). ${ }^{12}$ Thus our clinical outcome seems to be in the normal range that can be expected in these patient population.

Our re-operation rate of $14 \%$ is exactly the same as in the fusion group of the SLIP trial. All of our repeat surgeries were done to address instability. In the SLIP trial the reoperation rate was $34 \%$ in the decompression-alone group and all the surgeries were done to address instability. The follow-up times are comparable and it is unlikely that more patients will have surgeries for instability.

Our main finding is that a high number of patients develop micro-instability without any effect on clinical outcome. This might partially explain the findings in the Swedish trial.

As of this writing, Försth et al. have not provided the report on the radiographic data as announced in their article. We found that $47 \%$ of our patients developed an unstable slip after a mean follow-up of 65 months. A similar prospective study that relied on radiographs saw only a $8 \%$ progression rate of the slip. ${ }^{5}$ Our higher rate may be due to our more sensitive imaging modality. ${ }^{14,20,21}$ Thus there seems to be a subset of patients who develop morphological instability lacking clinical relevancy.

In contrast to previously published studies,, 316 our analysis did not show any correlation between disc height and instability. We speculate that the small number of patients in our study or the different assessment tool (MRI vs radiography) may explain this finding. Furthermore we did not see any adjacent-segment degeneration, which is frequently seen even after motion-preserving instrumented procedures. ${ }^{17}$

The analysis to find any preoperative predictors of instability did not show that disc height could be predictive. Although our findings are extremely limited by the size of our group, they corroborate the findings of Schär et al. ${ }^{25}$

The limitations of our study are obvious (small number, retrospective nature, selection bias related to patients' ability to get to the study facility).

The imaging modality that we used might also uncover findings due to its higher sensitivity. Indeed, the definition that we used for instability could be too sensitive, and we cannot prove that this movement did not exist already before the surgery. But, we reviewed the MR images again, looking for such movement at any other vertebral level, and we did not see it in any other segment in any of the 21 patients. This movement therefore can at least be described as abnormal, if not pathologic.

Our findings add an important contribution to the literature in that we have shown that there are patients who have a type of abnormal movement at the index level but are clinically satisfied. Furthermore, we show that microinstability-which was previously only speculated to develop in a high percentage of patients after sole-decompression procedures-actually exists., ${ }^{78,19}$ Both findings add important considerations to the question of whether the practice of recommending a fusion surgery as the upfront procedure in a patient with degenerative spondylolisthesis is justified ${ }^{8,15,24}$

Two questions arise from this study: 1) Do patients who do not show gross instability on conventional imaging studies necessarily need fusion procedures? 2) How many patients would have such instability on images obtained with upright MRI before the surgery? We hope to address these questions in the future.

\section{References}

1. Alimi M, Hofstetter CP, Pyo SY, Paulo D, Härtl R: Minimally invasive laminectomy for lumbar spinal stenosis in patients with and without preoperative spondylolisthesis: clinical outcome and reoperation rates. J Neurosurg Spine 22:339-352, 2015

2. Arnold PM: Minimally invasive spinal surgery and spinal stenosis. J Neurosurg Spine 22:337-338, 2015

3. Blumenthal C, Curran J, Benzel EC, Potter R, Magge SN, Harrington JF Jr, et al: Radiographic predictors of delayed instability following decompression without fusion for degenerative grade I lumbar spondylolisthesis. J Neurosurg Spine 18:340-346, 2013

4. Chan AK, Bisson EF, Bydon M, Glassman SD, Foley KT, Potts EA, et al: Laminectomy alone versus fusion for grade 1 lumbar spondylolisthesis in 426 patients from the prospective Quality Outcomes Database. J Neurosurg Spine 30:234241, 2018

5. Chang HS, Fujisawa N, Tsuchiya T, Oya S, Matsui T: Degenerative spondylolisthesis does not affect the outcome of unilateral laminotomy with bilateral decompression in patients with lumbar stenosis. Spine (Phila Pa 1976) 39:400-408, 2014 
6. Deyo RA, Mirza SK, Martin BI, Kreuter W, Goodman DC, Jarvik JG: Trends, major medical complications, and charges associated with surgery for lumbar spinal stenosis in older adults. JAMA 303:1259-1265, 2010

7. Donnarumma P, Tarantino R, Nigro L, Rullo M, Messina D, Diacinti D, et al: Decompression versus decompression and fusion for degenerative lumbar stenosis: analysis of the factors influencing the outcome of back pain and disability. $\mathbf{J}$ Spine Surg 2:52-58, 2016

8. El Tecle NE, Dahdaleh NS: Fusion surgery for lumbar spinal stenosis. N Engl J Med 375:597, 2016 (Letter)

9. Fischgrund JS, Mackay M, Herkowitz HN, Brower R, Montgomery DM, Kurz LT: 1997 Volvo Award winner in clinical studies. Degenerative lumbar spondylolisthesis with spinal stenosis: a prospective, randomized study comparing decompressive laminectomy and arthrodesis with and without spinal instrumentation. Spine (Phila Pa 1976) 22:2807-2812, 1997

10. Försth P, Ólafsson G, Carlsson T, Frost A, Borgström F, Fritzell P, et al: A randomized, controlled trial of fusion surgery for lumbar spinal stenosis. N Engl J Med 374:1413-1423, 2016

11. Ghogawala Z, Barker FG II, Benzel EC: fusion surgery for lumbar spinal stenosis. N Engl J Med 375:600-601, 2016

12. Ghogawala Z, Dziura J, Butler WE, Dai F, Terrin N, Magge $\mathrm{SN}$, et al: Laminectomy plus fusion versus laminectomy alone for lumbar spondylolisthesis. N Engl J Med 374:14241434,2016

13. Herkowitz HN, Kurz LT: Degenerative lumbar spondylolisthesis with spinal stenosis. A prospective study comparing decompression with decompression and intertransverse process arthrodesis. J Bone Joint Surg Am 73:802-808, 1991

14. Kanno H, Ozawa H, Koizumi Y, Morozumi N, Aizawa T, Ishii Y, et al: Changes in lumbar spondylolisthesis on axialloaded MRI: do they reproduce the positional changes in the degree of olisthesis observed on X-ray images in the standing position? Spine J 15:1255-1262, 2015

15. Kepler CK, Vaccaro AR, Hilibrand AS, Anderson DG, Rihn JA, Albert TJ, et al: National trends in the use of fusion techniques to treat degenerative spondylolisthesis. Spine (Phila Pa 1976) 39:1584-1589, 2014

16. Kitchen WJ, Mohamed M, Bhojak M, Wilby M: Neurogenic claudication secondary to degenerative spondylolisthesis: is fusion always necessary? Br J Neurosurg 30:662-665, 2016

17. Kuo CH, Huang WC, Wu JC, Tu TH, Fay LY, Wu CL, et al: Radiological adjacent-segment degeneration in L4-5 spondylolisthesis: comparison between dynamic stabilization and minimally invasive transforaminal lumbar interbody fusion. J Neurosurg Spine 29:250-258, 2018

18. Landi A, Gregori F, Mancarella C, Maiola V, Maccari E, Marotta N, et al: Lumbar spinal degenerative "microinstability": hype or hope? Proposal of a new classification to detect it and to assess surgical treatment. Eur Spine J 24 (Suppl 7):872-878, 2015

19. Landi A, Gregori F, Marotta N, Donnarumma P, Delfini R: Hidden spondylolisthesis: unrecognized cause of low back pain? Prospective study about the use of dynamic projections in standing and recumbent position for the individuation of lumbar instability. Neuroradiology 57:583-588, 2015

20. Niggemann P, Kuchta J, Hadizadeh D, Pieper CC, Schild $\mathrm{HH}$ : Classification of spondylolytic clefts in patients with spondylolysis or isthmic spondylolisthesis using positional MRI. Acta Radiol 58:183-189, 2017

21. Niggemann P, Simons P, Kuchta J, Beyer HK, Frey H, Grosskurth D: Spondylolisthesis and posterior instability. Acta Radiol 50:301-305, 2009

22. Pearson A, Blood E, Lurie J, Tosteson T, Abdu WA, Hillibrand A, et al: Degenerative spondylolisthesis versus spinal stenosis: does a slip matter? Comparison of baseline characteristics and outcomes (SPORT). Spine (Phila Pa 1976) 35:298-305, 2010

23. Radovanovic I, Urquhart JC, Ganapathy V, Siddiqi F, Gurr $\mathrm{KR}$, Bailey SI, et al: Influence of postoperative sagittal balance and spinopelvic parameters on the outcome of patients surgically treated for degenerative lumbar spondylolisthesis. J Neurosurg Spine 26:448-453, 2017

24. Resnick DK, Watters WC III, Sharan A, Mummaneni PV, Dailey AT, Wang JC, et al: Guideline update for the performance of fusion procedures for degenerative disease of the lumbar spine. Part 9: lumbar fusion for stenosis with spondylolisthesis. J Neurosurg Spine 21:54-61, 2014

25. Schär RT, Kiebach S, Raabe A, Ulrich CT: Reoperation rate after microsurgical uni- or bilateral laminotomy for lumbar spinal stenosis with and without low-grade spondylolisthesis: what do preoperative radiographic parameters tell us? Spine (Phila Pa 1976) 44:E245-E251, 2019

26. Sharma M, Ugiliweneza B, Aljuboori Z, Nuño MA, Drazin $\mathrm{D}$, Boakye M: Factors predicting opioid dependence in patients undergoing surgery for degenerative spondylolisthesis: analysis from the MarketScan databases. J Neurosurg Spine 29:271-278, 2018

27. Su BW, Vaccaro AR: Fusion surgery for lumbar spinal stenosis. N Engl J Med 375:597-598, 2016 (Letter)

28. Vasudeva VS, Chi JH: Fusion surgery for lumbar spinal stenosis. N Engl J Med 375:598, 2016 (Letter)

\section{Disclosures}

Dr. Weise reports receipt of honoraria from Medtronic and receipt of support for non-study-related clinical or research efforts from Boston Scientific.

\section{Author Contributions}

Conception and design: Duetzmann, Weise, H Frey. Acquisition of data: Kern, Mroe, H Frey, K Frey. Drafting the article: Duetzmann. Administrative/technical/material support: Setzer. Study supervision: Seifert.

\section{Supplemental Information \\ Current Affiliations}

Dr. Weise: Division of Neurosurgery, Dalhousie University, Halifax, NS, Canada.

\section{Correspondence}

Stephan Duetzmann: Goethe University Hospital Frankfurt, Frankfurt, Germany. stephan.duetzmann@gmail.com. 